\title{
Time-varying equilibrium rates in small open economies: Evidence for Canada
}

Tino Berger ${ }^{\dagger}$ und Bernd Kempa ${ }^{\ddagger}$

$34 / 2014$

${ }^{\dagger}$ CMR, University of Cologne, Germany

${ }^{\ddagger}$ Department of Economics, University of Münster, Germany 


\title{
Time-varying equilibrium rates in small open economies: Evidence for Canada
}

\author{
Tino Berger* $\quad$ Bernd Kempa ${ }^{\dagger}$
}

\begin{abstract}
This paper estimates equilibrium rates of macroeconomic aggregates for small open economies. We simultaneously identify the transitory and permanent components of output, inflation, the interest rate and the exchange rate by means of a multivariate trend-cycle decomposition. Realizations of the observed macroeconomic aggregates are explained in terms of unobserved equilibrium rates and unobserved transitory components. The transitory components of the variables are linked to each other through an aggregate demand equation, a Phillips curve, and an equation specifying the interest rate-exchange rate nexus. The model is then applied to Canadian data.
\end{abstract}

JEL Classification: C11, C32, E32, E43, F41

Keywords: unobserved components, potential output, natural rate of interest, equilibrium exchange rate

*University of Cologne, CMR, tino.berger@wiso.uni-koeln.de, Tel.: (+49)221-4702472, Albertus-Magnus-Platz, 50923 Koeln, Germany

$\dagger$ University of Muenster, Corresponding author, bernd.kempa@uni-muenster.de, Tel.: (+49)251-8328661, Universitaetsstrasse 14-16, 48143 Muenster, Germany 


\section{Introduction}

The identification and measurement of unobservable equilibrium rates of macroeconomic aggregates is an essential input in the formulation of policy recommendations. In terms of monetary policy, the neutral (equilibrium or natural) real interest rate is a key variable for assessing whether the monetary policy stance is contractionary or expansionary (Laubach and Williams, 2003). Moreover, the level of natural (or potential) output and the associated real-activity gap is an integral element of monetary policy rules, such as the Taylor-rule interest-rate reaction function (Taylor, 1993; Orphanides, 2008). In terms of fiscal policy, the output gap is an important measure of the economic cycle, and functions as an indicator of the sustainability of fiscal policy and the current fiscal stance (Koske and Pain, 2008).

One way to obtain empirical estimates of the unobservable gaps and equilibrium levels of macroeconomic aggregates is by means of unobserved components (UC) models. Such models utilize information from economic theory in a time-series approach in order to decompose realizations of observed macroeconomic aggregates into their unobserved equilibrium rates and unobserved transitory components. ${ }^{1}$ In UC models, pioneered by Harvey (1985), Watson (1986) and Clark (1987), trend and cycle are both treated as latent state variables, and modeled as non-stationary and mean-reverting processes, respectively. Applications of this framework include estimates of the natural rate of interest by relating the transitory interest rate to the output gap in an aggregate-demand equation (Laubach and Williams, 2003; Mésonnier and Renne, 2007), or estimates of the output gap from a bivariate system combining inflation and output on the basis of a New-Keynesian Phillips curve (Basistha and Nelson, 2007).

Whereas previous UC models are explicitly or implicitly designed for the U.S. economy or other large economic regions such as the euro area, we are not aware of any studies which specifically focus on small open economies. This paper tries to fill this gap. The characteristic feature of any such model is the prominent role it imparts on the exchange rate in the empirical identification strategy. The exchange rate is the most important relative price of a small open economy, and should constitute an integral element in the identification of the transitory and permanent components of output, inflation and the interest rate.

In our model, the real exchange rate is related to the output gap through the current account,

${ }^{1} \mathrm{UC}$ models can be viewed as a compromise between the class of agnostic time series approaches on the one hand and full-fledged macroeconomic DSGE models on the other. Purely statistical de-trending procedures such as the HP filter do not incorporate any information from economic theory, and can neither capture non-zero correlation of trend and cycle nor any potential transitory fluctuations in equilibrium rates. Alternatively, DSGE models are explicitly designed to identify transitory deviations of macroeconomic variables from their respective natural rates, and are not suited to trace the dynamic evolution of the natural rates themselves. 
influences inflation via its effect on import prices, and impacts the interest rate by inducing expectations of mean reversion of the real exchange rate towards its equilibrium level. In a small open economy, both aggregate demand and the Phillips curve contain the real exchange rate as an argument. As the interest gap may also be associated with an exchange rate misalignment through a potential interest rate-exchange rate nexus, the model is extended by an equation linking the real interest rate to the real exchange rate.

Besides adding to the UC literature in general, our model provides potentially useful information for economic policymakers. Taking explicit account of the exchange rate not only affects the decomposition of macroeconomic variables into their permanent and transitory components, but also allows for the identification of the permanent and transitory components of the exchange rate itself. In an open-economy context, deviations of the real exchange rate from its equilibrium level function as a signal of a country's competitiveness. The determination of equilibrium exchange rates is also important for a variety of issues in exchange rate economics, including assessments of currency misalignments, the decision of opting for fixed or flexible exchange rates, and questions regarding the reform of the international monetary system (MacDonald and Stein, 1999).

In the following we lay out a rather general structure of a UC model that should be applicable to any small open economy. However, in view of our subsequent application using Canadian data, we choose to incorporate some Canada-specific features into the model. This allows us to confront our results with previous studies on Canada. The plan of the paper is as follows: Section 2 introduces the model, Section 3 presents the estimation results, and Section 4 concludes.

\section{The model}

Our model follows the earlier UC literature by specifying the equilibrium rates as random walk processes, while relating the transitory components of the variables to each other through an aggregate demand equation and a Phillips curve. However, in contrast to previous literature, we propose a multivariate UC model specifically geared towards a small open economy. The model consists of inflation, $\pi$, output, $y$, the real interest rate, $r$, and the real effective exchange rate, $q$, the latter defined as the price of the home currency in terms of foreign exchange. The period$t$ observed levels of $y_{t}, r_{t}$ and $q_{t}$ can each be expressed as the sum of two components, their respective equilibrium levels, denoted by an asterisk, and their gaps in terms of deviations of the 
actual realizations from their equilibrium levels, denoted by a tilde:

$$
\begin{aligned}
& y_{t}=y_{t}^{*}+\tilde{y}_{t}, \\
& r_{t}=r_{t}^{*}+\tilde{r}_{t}, \\
& q_{t}=q_{t}^{*}+\tilde{q}_{t} .
\end{aligned}
$$

The inflation rate is modeled as a function of expected inflation, the output gap, and the exchange rate gap. As we later apply the model to Canadian data, we follow Basistha (2007) and Kichian (1999) who report a better fit for Canada when inflation is modeled in level data instead of first differences. We therefore specify the Phillips curve in levels, such that the mean of inflation is a constant. As there is strong evidence of mean shifts in Canadian inflation, we allow for breaks in this constant. The number and the timing of the breaks is determined by the Bai and Perron (1998) structural break test. ${ }^{2}$ We also use lagged inflation as a proxy for expected inflation.

$$
\pi_{t}=\bar{\pi}_{j}+b_{\pi} \pi_{t-1}+b_{y} \tilde{y}_{t}+b_{q} \Delta q_{t-1}+\eta_{t}^{\pi}
$$

where $\bar{\pi}_{j}$ is the mean value of inflation. The subscript $j$ refers to different values of $\bar{\pi}_{j}$ with $j=1, \ldots, \phi+1$, and $\phi$ denoting the number of structural breaks. Note that the exchange rate affects inflation directly through its first difference, and indirectly through the output gap. This way of modeling exchange rate effects in a small open economy was originally introduced by Ball (1999).

As suggested by Laubach and Williams (2003), we let the evolution of equilibrium output and the natural real interest rate be linked through the trend growth rate of potential output, $g$, modeled as a random walk:

$$
\begin{aligned}
& y_{t}^{*}=y_{t-1}^{*}+g_{t-1}+\eta_{t}^{y^{*}}, \\
& g_{t}=g_{t-1}+\eta_{t}^{g} \\
& r_{t}^{*}=c g_{t-1}+z_{t-1}, \\
& z_{t}=z_{t-1}+\eta_{t}^{z} .
\end{aligned}
$$

\footnotetext{
${ }^{2}$ Bai and Perron suggest to first examine two tests (the so called $U D \max$ and $W D \max$ tests) to check if there are any structural breaks. If these tests reject the null of no breaks, a sequential procedure to determine the number of breaks is used. This means computing a sequence of $\operatorname{SupFT}(l+1)$ statistics to test the null of $l$ breaks against the alternative of $l+1$ breaks. A detailed description of this test can be found in Bai and Perron (1998) and Rapach and Wohar (2005).
} 
Beside technology parameters driving the trend growth rate of output, the natural interest rate is also influenced by preference parameters. These are captured in Eqs. (7) and (8) by the variable $z_{t}$, itself assumed to follow a random walk.

The aggregate demand equation relates the output gap to its own lags and a moving average of the lagged real interest rate gap as in Laubach and Williams (2003) and Mésonnier and Renne (2007). We also include a moving average of the lagged real exchange rate as an additional argument to explicitly allow for effects arising from the trade sector and the current account of a small open-economy,

$$
\tilde{y}_{t}=A_{y}(L) \tilde{y}_{t-1}+A_{r}(L) \tilde{r}_{t-1}+A_{q}(L) \tilde{q}_{t-1}+\eta_{t}^{\tilde{y}}
$$

where the lag polynomials are defined as $A_{i}(L)=a_{i 0}+a_{i 1} L+\ldots+a_{i n} L^{n}$ for $A_{i}=\left\{A_{y}, A_{r}, A_{q}\right\}$. The expected signs of the coefficients $A_{q}(L)$ are negative, as any realization of the real exchange rate below its equilibrium level $(\tilde{q}<0)$ is associated with an undervaluation of the home currency, improving the current account and thus raising the level of economic activity above potential $(\tilde{y}>0)$.

Finally, the equilibrium level of the effective real exchange rate is assumed to follow an independent random walk process with serially uncorrelated innovations:

$$
q_{t}^{*}=q_{t-1}^{*}+\eta_{t}^{q^{*}}
$$

while its transitory deviations from equilibrium are modeled as a mean-reverting process,

$$
\tilde{q}_{t}=D_{q}(L) \tilde{q}_{t-1}+\eta_{t}^{\tilde{q}}
$$

where the lag polynomial is defined as $D_{q}(L)=d_{q 0}+d_{q 1} L+\ldots+d_{q n} L^{n}$. In order to close the model, we specify an additional equation tying the real interest rate gap to the real exchange rate gap:

$$
\begin{gathered}
\tilde{r}_{t}=\gamma \tilde{q}_{t-1}+\kappa_{t-1}, \\
\kappa_{t}=\rho \kappa_{t-1}+\eta_{t}^{\kappa} .
\end{gathered}
$$

Nonzero realizations of the exchange rate gap are associated with expectations of mean reversion 
of the real exchange rate. For example, if the exchange rate happens to be overvalued $(\tilde{q}>0)$, then expectations of a subsequent depreciation of the home currency induce capital exports unless or until the home interest rate temporarily increases to compensate investors for the expected capital loss on home assets $(\tilde{r}>0)$. The error term $\kappa$, modeled as a mean-reverting process in Eq. (13), captures all factors which may impinge on the interest rate-exchange rate nexus, such as time-varying risk premia or any other distortions in international capital markets.

Eq. (12) is reminiscent of the uncovered interest rate parity (UIP) condition, which itself has little empirical support, particularly when tested using financial instruments with relatively short maturities of 12 months or less. ${ }^{3}$ However, there are two major differences which distinguish the interest rate-exchange rate nexus of Eq. (12) from traditional UIP specifications. First, the conjectured relationship is between the gaps, and not the levels of interest and exchange rates. Eq. (12) is thus a statement of the disequilibrium dynamics between these variables, whereas UIP is an equilibrium phenomenon. Second, Eq. (12) is stipulated in terms of the home interest rate gap only, and it does not require the home and foreign equilibrium interest rates to be identical. In fact, movements of the foreign equilibrium interest rate, which may be governed by a relationship similar to Eqs. (7) and (8), does not affect the home interest rate gap (though it may be linked to the home equilibrium interest rate as long as there is correlation between the trend growth rates of potential output in the home and foreign economies).

The model given by Eqs. (1)-(13) can be cast into a linear Gaussian state space model of the following general form ${ }^{4}$

$$
\begin{array}{rlrl}
Y_{t} & =Z \xi_{t}+A X_{t}+\varepsilon_{t}, & \varepsilon_{t} & \sim N(0, H), \\
\xi_{t}=T \xi_{t-1}+K \eta_{t}, & \eta_{t} \sim N(0, Q), \quad t=1, \ldots, v,
\end{array}
$$

where $Y_{t}$ is a $p \times 1$ vector of $p$ observed endogenous variables, modeled in the observation equation, Eq. (14), $X_{t}$ is a vector of exogenous variables, and $\xi_{t}$ is a $m \times 1$ vector of $m$ unobserved states, modeled in the state equation, Eq. (15). The vectors $\varepsilon_{t}$ and $\eta_{t}$ are assumed to hold mutually independent Gaussian error terms with the former representing measurement errors and the latter structural shocks. We analyze the state space model from a Bayesian point of view, i.e. we use prior information to down-weight the likelihood function in regions of the parameter space that are inconsistent with out-of-sample information and/or in which the structural model is not

\footnotetext{
${ }^{3}$ The results from long-horizon data are much more encouraging, see e.g. Chinn and Meredith (2004, 2005).

${ }^{4}$ See e.g. Durbin and Koopman (2001) for an extensive overview of state space models.
} 
interpretable. $^{5}$

\section{Results}

\subsection{Data}

We use seasonally adjusted quarterly data for Canada from 1975Q2 to 2010Q4 taken from the OECD Main Economic Indicators and the International Monetary Fund, International Financial Statistics. Inflation is the annualized first difference of the $\log$ of the seasonally adjusted CPI, output is quarterly GDP in natural logs multiplied by 100, and the exchange rate is Canada's real effective exchange rate. Our measure of the (ex post) interest rate is the real three month T-Bill rate. Starting in 1975 implies (i) that we only focus on the post Bretton-Woods era and (ii) that we do not need to address the productivity slowdown in real GDP in the early 1970s.

The transitory components of output and inflation include two lagged dependent variables, as is standard for unobserved component models when quarterly data are used. The cyclical exchange rate also appears with two lags in the output gap in order to account for potentially delayed balance-of-payments responses to changes in the exchange rate. Following Laubach and Williams (2003) and Mésonnier and Renne (2007) we include one lag of the cyclical interest rate in the output gap equation.

\subsection{Structural breaks in the mean of inflation}

Table 1 presents the results of the BP tests on structural breaks in inflation.

Table 1 about here

Both the $W D_{\max }$ and the $U D_{\max }$ test statistic clearly reject the null hypothesis of no structural breaks in inflation at conventional confidence levels. The sequential analysis also rejects the null hypothesis of no breaks against the alternative hypothesis of one break as well as the null of one break against the alternative hypothesis of two structural breaks. However, more than two breaks are not found. The detected break dates are 1982:Q3 and 1991:Q1. ${ }^{6}$

\footnotetext{
${ }^{5}$ The exact specification of the state space form as well as details on the estimation procedure are provided in the Appendix.

${ }^{6}$ The break dates are similar to those in Basistha (2007).
} 


\subsection{Prior distribution of the parameters}

Prior information on the unknown parameter vector is included in the analysis through the prior density. The prior distribution is assumed to be Gaussian for all parameters except for the variance parameters which are assumed to be gamma distributed. Detailed information on the prior parameter distributions can be found in the first columns of Table 2. As stated above, the main motivation for setting these priors is to down-weight the likelihood function in regions of the parameter space that are inconsistent with out-of-sample information and/or in which the structural model is not interpretable. Previous estimates as well as economic theory give us an idea about the approximate value of the model's parameters. However, using previous studies to set priors should be done with caution particularly if these studies consider the same time period. We therefore use previous estimates only as a rough indication for the prior means but choose the prior variance fairly loose. The bivariate unobserved component model for Canada of Basistha (2007) provides an indication for the parameter values in output.

Table 2 about here

The prior distributions of the autoregressive parameters are chosen such that their $90 \%$ intervals allow for white noise cycles, i.e. the confidence bands of the sum of the autoregressive parameters include the zero, as well as values near unity. ${ }^{7}$ Thus the prior distributions of the persistence parameters are non-informative, i.e. the posteriors are driven only by the likelihood.

We do not want to impose any strong prior beliefs on the structural parameters $a_{q}$ and $\gamma$. Although we expect a transitory depreciation of the real exchange rate to raise the output gap, we specify flat priors with zero means of the parameters for the impact reaction as well as the delayed response, $a_{q 0}$ and $a_{q 1}$, such that the dynamics of the current account reaction remain completely unrestricted, and are left solely to the data. Similarly, we set a flat prior with zero mean for $\gamma$ to test whether our conjecture about the interest rate-exchange rate nexus stipulated in Eq. (12) is confirmed by the data.

More informative priors are used for $b_{y}, c, a_{r}$ and $b_{q}$ as we can draw on estimates for these parameters from other studies. We follow Laubach and Williams (2003) and set the prior mean for the interest rate effect to $a_{r 0}=-0.1$. These authors also estimate the slope of the Phillips curve

\footnotetext{
${ }^{7}$ Note that we restrict the sum of the autoregressive parameters to be smaller than unity in absolute value as the model would otherwise not be identified.
} 
to be around $b_{y}=0.5$, and the impact of potential output growth on the natural real interest rate in the vicinity of unity in quarterly data. This translates into a value of $c=4$ for our annualized inflation data. Finally, the parameter $b_{q}$ captures the exchange rate effect on CPI inflation, the size of which is determined by the product of two factors. One is the extent of exchange rate pass-through on import prices, which is estimated by Campa and Goldberg (2005) to be 0.75 for Canada. The other is the import share in the consumption basket, which is about $33 \%$ for Canada. Taken together, these factors inform our prior of $b_{q}=-0.25$. Despite these specific prior estimates, we choose rather wide confidence intervals for all parameters.

\subsection{Posterior distribution of the parameters}

The last two columns of Table 2 show the posterior mean and the $10 \%$ and $90 \%$ percentiles of the posterior distribution of all parameters. Similar to other studies for industrialized countries we find the output gap to be relatively persistent. Likewise, the sum of the AR parameters in the exchange rate gap is 0.94 , implying a low degree of mean reversion of the real exchange rate. The result of very persistent transitory exchange rate shocks is also consistent with other estimates in the literature (see e.g Engel and Kim, 1999; Rogoff, 1996).

The posterior mean of $a_{r_{0}}$ turns out to be smaller than the corresponding estimates for the U.S. and for the euro area, as reported by Laubach and Williams (2003) and Mésonnier and Renne (2007), respectively. This evidence implies that the cyclical interest rate matters less for Canada than it does for the euro area or the U.S. At the same time, the transitory real effective exchange rate turns out to be an important determinant of the Canadian output gap. Whereas an appreciation raises the output gap on impact $\left(a_{q_{0}}>0\right)$, the lagged effect is found to be negative $\left(a_{q_{1}}<0\right)$. This adjustment pattern suggests the presence of a $J$-curve effect in the balance of payments, with the Marshall-Lerner condition of a normal reaction of the current account to changes in the exchange rate being violated in the very short run.

In terms of the evidence on inflation, we find that the posterior mean of the slope of the Phillips curve is smaller than our prior mean. This result may be interpreted in terms of a "flattening" of the Phillips curve, as documented for the United States by Roberts (2006) and for Canada by Beaudry and Doyle (2000). We also find the posterior of the pass-through coefficient $b_{q}$ to be substantially smaller than our prior. This result is in line with much recent empirical evidence of a decline in pass-through coefficients for a broad group of countries in general, and for Canada in particular, where it is considered to be a reflection of the improved monetary policy credibility of 
the Bank of Canada associated with the adoption of formal inflation targeting in the early 1990s (Bailliu et al., 2010).

Finally, our conjecture of a positive association between the real interest rate gap and the real exchange rate gap is confirmed by significantly positive realizations of the posterior mean of the parameter $\gamma$, where the low variance of the posterior distribution points to the appropriateness of our specification of the interest rate-exchange rate nexus as stipulated in Eq. (12).

\subsection{Posterior distribution of the states}

Fig. 1 displays the trend and cyclical components of output, the real interest rate and the real exchange rate together with the $10 \%$ and $90 \%$ percentiles of their respective posterior distributions. We find the natural level of output to evolve rather smoothly throughout the sample period, where the shape and magnitude of the Canadian output gap is very similar to the estimates reported by Basistha (2007). The shaded areas indicate Canadian recessions as defined by the OECD. It turns out that the estimated output gap picks up the business cycle turning points quite accurately. Similarly, our estimate of the natural real interest rate is in line with results from previous literature. For example, Lam and Tkacz (2004) estimate policy-neutral interest rates for Canada within a DSGE framework, in which their measure of the natural Canadian interest rate displays rather little time variation.

Figure 1 about here

As in previous permanent-transitory decompositions, we find that the permanent component of the Canadian real exchange rate exhibits substantial time variability, but is more stable than the actual real exchange rate itself (Cumby and Huizinga, 1991; Clarida and Gali, 1994). The equilibrium rate of the Canadian dollar depreciates gradually between the early 1980s and mid1990s. This finding is in line with results obtained by Clark and MacDonald (2004) who estimate behavioral equilibrium exchange rates (BEER) and permanent equilibrium exchange rates (PEER) for Canada. ${ }^{8}$ The downward movement of the equilibrium real exchange rate is reversed in the mid- to late-1990s, giving way to a gradual appreciation throughout the 2000s. Similar evidence of

\footnotetext{
${ }^{8}$ BEER connects the observed real exchange rate with its long-run fundamental determinants, whereas PEER uses time-series estimators to decompose real exchange rates into their permanent and transitory components, with the permanent component defined as a measure of the equilibrium exchange rate. Such decompositions can be obtained by means of various statistical techniques, such as univariate or multivariate Beveridge-Nelson decompositions, structural vector-autoregressions, or cointegration-based estimation techniques. For a detailed discussion of these and other equilibrium exchange rate concepts and further references, see MacDonald (2000) and Driver and Westaway (2004).
} 
a reversal of Canada's trend rate of the real exchange rate has been reported by Betts and Kehoe (2006), who detect a close association between the long-run movements of the real exchange rate and the relative price of Canadian non-traded to traded goods. The long swings of the equilibrium exchange rate identified by our UC model are also roughly in line with those identified by MacDonald (2012) on the basis of purchasing power parity (PPP) exchange rates.

Comparing the actual and equilibrium levels of the real exchange rate suggests that the Canadian dollar has experienced a number of substantial deviations from equilibrium throughout the sample period. In particular, our UC model identifies two periods of significant undervaluation in the late 1970s and the late 1990s to early 2000s, and one occasion of a significant overvaluation in the late 1980s to early 1990s. All three episodes occur in the process of multilateral exchange rate adjustments. The undervaluation at the beginning of the sample period mirrors the long decline of the Canadian dollar during the second half of the 1970s associated with the widespread currency realignments after the breakdown of the Bretton-Woods system of fixed exchange rates. The overvaluation of the late 1980s follows in the wake of the coordinated attempts at weakening the U.S. dollar in the second half of the 1980s, which resulted in temporary overvaluations of the Canadian dollar and other major currencies. Finally, the significant undervaluation of the Canadian dollar in the late 1990s and early 2000s mirrors the appreciation of the U.S. dollar, which was considered to be a safe haven currency following a series of major currency and banking crises in Southeast Asia, Brazil, and Russia in the second half of the 1990s (Bailliu et al., 2005).

Although all of the natural rates evolve rater smoothly, the degrees of smoothness do in fact differ between the individual time series. It should be noted that these differences in smoothness are determined endogenously by our UC model, and could therefore not be captured using a standard HP filter with constant smoothness parameters.

Figure 2 about here

Fig. 2 shows the prior together with the posterior distributions for all parameters. Most of the posterior parameter variances turn out to be substantially narrower than the prior distributions. This evidence suggests that our results are driven primarily by the data rather than being informed by our prior beliefs about the appropriate parameter specification. 


\subsection{Comparison to HP filtered trends}

Here we briefly report results from applying a standard Hodrick-Prescott (HP) filter as an alternative to identifying the equilibrium rates in our data. Fig. 3 contrasts the equilibrium exchange rate, potential output growth, the natural rate of interest and potential output from our UC model with those obtained from a HP filter with the smoothing parameter set to 1600. By construction, the HP filtered trends follow the actual data rather closely, whereas the UC model generates larger and more persistent deviations from the respective equilibrium values. These differences in the identification of the trends arise because the HP filter is a simple univariate de-trending method, whereas UC models identify the natural rates and their transitory components by combining filter techniques with a structural economic model. Our UC model for a small open economy links the transitory components to each other through an aggregate demand equation, a Phillips curve, and an equation relating the interest rate to the exchange rate. These linkages of the transitory components in conjunction with the stochastic law of motion specified for the trend and transitory components allows for a model-based identification of the trends and the corresponding gaps.

Figure 3 about here

As becomes apparent from Fig. 3, the equilibrium rates identified from the UC model and the HP filter turn out to be rather similar for both the output level and for output growth, but display some discernible differences with respect to the natural rate of interest and the equilibrium exchange rate. In particular, the UC model finds both natural rates to be lower in the latter half of the 1980s and early 1990s, and higher in the late 1990s and early 2000s, when each is compared to their HP filtered trends. This pattern can be motivated in economic terms by noting that the Canadian effective real exchange rate has been overvalued in the first, and undervalued in the second of these periods. According to our model, an overvaluation of the real exchange rate is associated with depreciation expectations which in turn raise the transitory real interest rate above its natural rate. Hence the natural real interest rate has to be lower in order to accommodate the positive interest rate gap for any given realization of the actual real interest rate. A similar reasoning applies for the case of undervaluation.

\subsection{Comparison to a constant GDP growth model}

In our (baseline) UC model, we have followed Laubach and Williams (2003) by linking the natural real interest rate to a time-varying trend growth rate of potential output. As an alternative 
specification, in this section we briefly report results from re-estimating the model with a constant output growth rate. This exercise allows us to assess the extent to which the identification of the equilibrium interest rate depends on this particular modeling choice.

Figure 4 about here

Fig. 4 provides a graphical comparison of the dynamics of the natural rate of interest for the two versions of the model. As in the case of HP filtered trends, it turns out that the constant growth model leads to a rather smooth interest rate path. ${ }^{9}$ In particular, the UC model again finds the natural rate to be lower in the late 1980s and early 1990s, and higher in the late 1990s. However, the differences with the constant growth model are much smaller relative to those generated from HP filtered trends. Hence, although long-term growth variation is an important factor for the determination of the natural interest rate on theoretical grounds, it has limited practical value for the actual estimates. ${ }^{1011}$ Nevertheless, the UC model allows for a more structural interpretation of the equilibrium interest rate. A variance decomposition of the equilibrium interest rate generated by our UC model into the contribution of time-varying potential output growth and the contribution of the purely stochastic part $z_{t}$, reveals that the former explains $42 \%$ of its variance. In contrast, the stochastic $z_{t}$ in the constant growth model also incorporates the dynamics of the omitted time-varying potential output growth rate.

\section{Conclusion}

A growing literature utilizes unobserved components (UC) models to estimate equilibrium rates of macroeconomic aggregates by means of multivariate trend-cycle decompositions. Such models are geared towards the U.S. economy or other large economic regions like the euro area. At the same time, there appear to be no models which specifically focus on the case of a small open economy. We try to fill this gap by specifying and estimating a UC model which imparts a prominent role to the exchange rate in the empirical identification strategy. In UC models, realizations of observed macroeconomic aggregates are explained in terms of unobserved equilibrium rates and unobserved transitory components. We follow the earlier UC literature by specifying the equilibrium rates as random walk processes, while relating the transitory components of the variables to each other

\footnotetext{
${ }^{9}$ The growth rate of potential output is estimated to be 0.68 , corresponding to an average annualized growth rate of $2.72 \%$.

${ }^{10} \mathrm{We}$ are grateful to an anonymous referee for pointing this out to us.

${ }^{11}$ Similar evidence obtains with respect to the output decomposition into trend and cycle, where the output gaps from the two models show a correlation of $91 \%$. Detailed results are available upon request.
} 
through an aggregate demand equation and a Phillips curve. In our model for the small open economy, both aggregate demand and the Phillips curve contain the real exchange rate as an argument. The model is further extended by an equation linking the real interest rate to the real exchange rate. The real exchange rate gap is related to the output gap through the current account, influences the inflation gap via its effect on import prices, and impacts the interest rate by inducing expectations of mean reversion of the real exchange rate towards its equilibrium level. The model also allows for the identification of the permanent and transitory components of the exchange rate itself. We apply the model to Canada as an archetypal small open economy.

We find natural output, the equilibrium real interest and exchange rates, as well as trend inflation to evolve rather smoothly throughout the sample period. Whereas this evidence is in line with results from previous literature, our results also imply that the cyclical interest rate matters less for Canada than it does for the euro area or the U.S. At the same time, the transitory real effective exchange rate turns out to be an important determinant of the Canadian output gap. Finally, our model also yields an estimate of the equilibrium real exchange rate. We find that our results for Canada are similar to those obtained using alternative equilibrium concepts such as purchasing power parity or behavioral and permanent equilibrium exchange rates. 


\section{References}

Bai, J., Perron, P., 1998. Estimating and testing linear models with multiple structural changes. Econometrica 66, 47-78.

Bailliu, J., Dib, A., Schembri, L., 2005. Multilateral adjustment and the Canadian dollar. In: Canada and the Global Economy. Bank of Canada, pp. 55-94.

Bailliu, J., Dong, W., Murray, J., 2010. Has exchange rate pass-through really declined? Some recent insights from the literature. Bank of Canada Review Autumn 2010, 1-8.

Ball, L., 1999. Policy rules for open economies. In: Taylor, J. (Ed.), Monetary Policy Rules. The University of Chicago Press, pp. 129-156.

Basistha, A., 2007. Trend-cycle correlation, drift break and the estimation of trend and cycle in Canadian GDP. Canadian Journal of Economics 40, 584-606.

Basistha, A., Nelson, C. R., 2007. New measures of the output gap based on the forward-looking new Keynesian Phillips curve. Journal of Monetary Economics 54, 498-511.

Bauwens, L., Lubrano, M., Richard, J., 1999. Bayesian Inference in Dynamic Econometric Models. Oxford University Press.

Beaudry, P., Doyle, M., 2000. What happened to the Phillips curve in the 1990s in Canada? Proceedings of a conference, Bank of Canada. In: Price Stability and the Long-Run Target for Monetary Policy. pp. 51-82.

Betts, C., Kehoe, T., 2006. U.S. real exchange rate fluctuations and measures of the relative price of goods. Journal of Monetary Economics 53, 1297-1326.

Campa, J., Goldberg, L. S., 2005. Exchange rate pass-through into import prices. The Review of Economics and Statistics 87 (4), 679-690.

Chinn, M. D., Meredith, G., 2004. Monetary policy and long-horizon uncovered interest parity. IMF Staff Papers 51 (3), 409-430.

Chinn, M. D., Meredith, G., 2005. Testing uncovered interest parity at short and long horizons during the post-bretton woods era. NBER Working Papers 11077, National Bureau of Economic Research, Inc. 
Clarida, R., Gali, J., 1994. Sources of real exchange rate fluctuations: How important are nominal shocks? In: Carnegie-Rochester Conference Series on Public Policy. Vol. 41. pp. 1-56.

Clark, P., 1987. The cyclical component of U.S. economic activity. Quarterly Journal of Economics $102,797-814$.

Clark, P. B., MacDonald, R., 2004. Filtering the beer: A permanent and transitory decomposition. Global Finance Journal 15, 29-56.

Cumby, R. E., Huizinga, J., 1991. The predictability of real exchange rate changes in the short and long run. Japan and the World Economy 3, 17-38.

Driver, R. L., Westaway, P. F., 2004. Concepts of Equilibrium Exchange Rates. Bank of England working paper 248, Bank of England.

Durbin, J., Koopman, S., 2001. Time Series Analysis by State Space Methods. Oxford University Press.

Engel, C., Kim, C., 1999. The long-run U.S./U.K. real exchange rate. Journal of Money, Credit and Banking 31, 335-56.

Geweke, J., 1989. Bayesian inference in econometric models using Monte Carlo integration. Econometrica 57, 1317-1339.

Harvey, A., 1985. Trends and cycles in macroeconomic time series. Journal of Business and Economic Statistics 3, 216-227.

Kichian, M., 1999. Measuring potential output within a state-space framework. Working Paper 99-9, Bank of Canada.

Koske, I., Pain, N., 2008. The usefulness of output gaps for policy analysis. OECD Economics Department Working Papers 621, OECD Publishing.

Lam, J., Tkacz, G., 2004. Estimating policy-neutral interest rates for Canada using a dynamic stochastic general-equilibrium framework. Bank of Canada Working Paper 2004-9.

Laubach, T., Williams, J. C., 2003. Measuring the natural rate of interest. The Review of Economics and Statistics 85, 1063-1070.

MacDonald, R., 2000. Concepts to calculate equilibrium exchange rates: An overview. Discussion Paper 3/00, Deutsche Bundesbank, Research Centre. 
MacDonald, R., 2012. Do Relative Canada/U.S. prices equate to the Exchange Rate? Economic Insights, Statistics Canada, Ottawa.

MacDonald, R., Stein, J. L., 1999. Equilibrium Exchange Rates. Kluwer Academic Publishers.

Mésonnier, J.-S., Renne, J.-P., 2007. A time-varying natural rate of interest for the euro areanatural rate of interest for the euro area. European Economic Review 51 (7), 1768-1784.

Orphanides, A., 2008. Taylor rules. In: Durlauf, S., Blume, L. (Eds.), The New Palgrave Dictionary of Economics, 2nd Edition. Palgrave Macmillan, Basingstoke, UK.

Rapach, D. E., Wohar, M. E., 2005. Regime changes in international real interest rates: Are they a monetary phenomenon? Journal of Money, Credit and Banking 37, 887-906.

Roberts, J., 2006. Monetary policy and inflation dynamics. International Journal of Central Banking $2,193-230$.

Rogoff, K., 1996. The purchasing power parity puzzle. Journal of Economic Literature 34, 647-668.

Taylor, J. B., 1993. Discretion versus policy rules in practice. Carnegie-Rochester Conference Series on Public Policy 39 (1), 195-214.

Watson, M., 1986. Univariate detrending methods with stochastic trends. Journal of Monetary Economics 18, 49-75. 


\section{Appendix}

State space representation of the model in (1)-(13)

$Y_{t}=\left[\begin{array}{llll}y_{t} & r_{t} & q_{t} & \pi_{t}\end{array}\right]^{\prime} ; \quad X_{t}=\left[\begin{array}{lllll}D U_{1} & D U_{2} & D U_{3} & \pi_{t-1} & \Delta q_{t-1}\end{array}\right]^{\prime} ;$

$D U_{1}, D U_{2}$, and $D U_{3}$ are dummy variables to capture the mean shifts in inflation.

$\xi_{t}=\left[\begin{array}{lllllllllll}y_{t}^{*} & g_{t} & \tilde{y}_{t} & \tilde{y}_{t-1} & r_{t}^{*} & \tilde{r}_{t} & \kappa_{t} & q_{t}^{*} & \tilde{q}_{t} & \tilde{q}_{t-1} & z_{t}\end{array}\right]^{\prime}$

$Z=\left[\begin{array}{ccccccccccc}1 & 0 & 1 & 0 & 0 & 0 & 0 & 0 & 0 & 0 & 0 \\ 0 & 0 & 0 & 0 & 1 & 1 & 0 & 0 & 0 & 0 & 0 \\ 0 & 0 & 0 & 0 & 0 & 0 & 0 & 1 & 1 & 0 & 0 \\ 0 & 0 & b_{y} & 0 & 0 & 0 & 0 & 0 & 0 & 0 & 0\end{array}\right], H=\left[\begin{array}{cccc}0 & 0 & 0 & 0 \\ 0 & 0 & 0 & 0 \\ 0 & 0 & 0 & 0 \\ 0 & 0 & 0 & \sigma_{\eta_{\pi}}^{2}\end{array}\right], A=\left[\begin{array}{ccccc}0 & 0 & 0 & 0 & 0 \\ 0 & 0 & 0 & 0 & 0 \\ 0 & 0 & 0 & 0 & 0 \\ \bar{\pi}_{1} & \bar{\pi}_{2} & \bar{\pi}_{3} & b_{\pi} & b_{q}\end{array}\right]$

$T=\left[\begin{array}{ccccccccccc}1 & 1 & 0 & 0 & 0 & 0 & 0 & 0 & 0 & 0 & 0 \\ 0 & 1 & 0 & 0 & 0 & 0 & 0 & 0 & 0 & 0 & 0 \\ 0 & 0 & a_{y_{0}} & a_{y_{1}} & 0 & a_{r_{0}} & 0 & 0 & a_{q_{0}} & a_{q_{1}} & 0 \\ 0 & 0 & 1 & 0 & 0 & 0 & 0 & 0 & 0 & 0 & 0 \\ 0 & c & 0 & 0 & 0 & 0 & 0 & 0 & 0 & 0 & 1 \\ 0 & 0 & 0 & 0 & 0 & 0 & 1 & 0 & \gamma & 0 & 0 \\ 0 & 0 & 0 & 0 & 0 & 0 & \rho & 0 & 0 & 0 & 0 \\ 0 & 0 & 0 & 0 & 0 & 0 & 0 & 1 & 0 & 0 & 0 \\ 0 & 0 & 0 & 0 & 0 & 0 & 0 & 0 & d_{q_{0}} & d_{q_{1}} & 0 \\ 0 & 0 & 0 & 0 & 0 & 0 & 0 & 0 & 1 & 0 & 0 \\ 0 & 0 & 0 & 0 & 0 & 0 & 0 & 0 & 0 & 0 & 1\end{array}\right] ; K=\left[\begin{array}{ccccccc}1 & 0 & 0 & 0 & 0 & 0 & 0 \\ 0 & 1 & 0 & 0 & 0 & 0 & 0 \\ 0 & 0 & 1 & 0 & 0 & 0 & 0 \\ 0 & 0 & 0 & 0 & 0 & 0 & 0 \\ 0 & 0 & 0 & 0 & 0 & 0 & 0 \\ 0 & 0 & 0 & 0 & 0 & 0 & 0 \\ 0 & 0 & 0 & 1 & 0 & 0 & 0 \\ 0 & 0 & 0 & 0 & 1 & 0 & 0 \\ 0 & 0 & 0 & 0 & 0 & 1 & 0 \\ 0 & 0 & 0 & 0 & 0 & 0 & 0 \\ 0 & 0 & 0 & 0 & 0 & 0 & 1\end{array}\right] ;$

$\operatorname{diag}(Q)=\left[\begin{array}{lllllll}\sigma_{\eta_{y^{*}}}^{2} & \sigma_{\eta_{g}}^{2} & \sigma_{\eta_{\tilde{y}}}^{2} & \sigma_{\eta_{\kappa}}^{2} & \sigma_{\eta_{q^{*}}}^{2} & \sigma_{\eta_{\tilde{q}}}^{2} & \sigma_{\eta_{z}}^{2}\end{array}\right]^{\prime}$

\section{Parameter estimation}

We treat $\psi$ as a random parameter vector with a known prior density $p(\psi)$ and estimate the posterior densities $p(\psi \mid Y)$ for the parameter vector $\psi$ and $p\left(\widehat{\xi}_{t} \mid Y\right)$ for the smoothed state 
vector $\widehat{\xi}_{t}$, where $Y$ denotes the stacked vector $\left(Y_{1}^{\prime}, \ldots, Y_{n}^{\prime}\right)^{\prime}$ by combining information contained in $p(\psi)$ and the sample data. This boils down to calculating the posterior mean $\bar{\imath}$

$$
\bar{\iota}=E[\iota(\psi) \mid Y]=\int \iota(\psi) p(\psi \mid Y) d \psi
$$

where $\iota$ is a function which expresses the moments of the posterior densities $p(\psi \mid Y)$ and $p\left(\widehat{\xi}_{t} \mid Y\right)$ in terms of the parameter vector $\psi$. In principle, the integral in Eq. $(A-1)$ can be evaluated numerically by drawing a sample of $n$ random draws of $\psi$, denoted $\psi^{(i)}$ with $i=1, \ldots, n$, from $p(\psi \mid Y)$ and then estimating $\iota$ by the sample mean of $\iota(\psi)$. As $p(\psi \mid Y)$ is not a density with known analytical properties, such a direct sampling method is not feasible, though. Therefore, we use importance sampling. The idea is to use an importance density $\iota(\psi \mid Y)$ as a proxy for $p(\psi \mid Y)$, where $\iota(\psi \mid y)$ should be chosen as a distribution that can be simulated directly and is as close to $p(\psi \mid Y)$ as possible. By Bayes' theorem and after some manipulations, Eq. $(A-1)$ can be rewritten as

$$
\bar{\iota}=\frac{\int \iota(\psi) z^{\iota}(\psi, Y) \iota(\psi \mid Y) d \psi}{\int z^{\iota}(\psi, Y) \iota(\psi \mid Y) d \psi}
$$

with

$$
z^{\iota}(\psi, Y)=\frac{p(\psi) p(Y \mid \psi)}{\iota(\psi \mid Y)}
$$

Using a sample of $n$ random draws $\psi^{(i)}$ from $\iota(\psi \mid Y)$, an estimate $\bar{\iota}_{n}$ of $\bar{\iota}$ can then be obtained as

$$
\bar{\iota}_{n}=\frac{\sum_{i=1}^{n} \iota\left(\psi^{(i)}\right) z^{\iota}\left(\psi^{(i)}, Y\right)}{\sum_{i=1}^{n} z^{\iota}\left(\psi^{(i)}, Y\right)}=\sum_{i=1}^{n} w_{i} \iota\left(\psi^{(i)}\right),
$$

with $w_{i}$

$$
w_{i}=\frac{z^{\iota}\left(\psi^{(i)}, Y\right)}{\sum_{i=1}^{n} z^{\iota}\left(\psi^{(i)}, Y\right)} .
$$

The weighting function $w_{i}$ reflects the importance of the sampled value $\psi^{(i)}$ relative to other sampled values. Geweke (1989) shows that if $\iota(\psi \mid Y)$ is proportional to $p(\psi \mid Y)$, and under a number of weak regularity conditions, $\bar{\iota}_{n}$ will be a consistent estimate of $\bar{\iota}$ for $n \rightarrow \infty$. As an importance density $\iota(\psi \mid Y)$, we take a large sample normal approximation to $p(\psi \mid Y)$, i.e.

$$
\iota(\psi \mid Y)=N(\widehat{\psi}, \widehat{\Omega})
$$


where $\widehat{\psi}$ is the mode of $p(\psi \mid Y)$ obtained from maximizing

$$
\log p(\psi \mid Y)=\log p(Y \mid \psi)+\log p(\psi)-\log p(Y)
$$

with respect to $\widehat{\psi}$ and where $\widehat{\Omega}$ denotes the covariance matrix of $\widehat{\psi}$. Note that $p(Y \mid \psi)$ is given by the likelihood function derived from the Kalman filter and we do not need to calculate $p(Y)$ as it does not depend on $\psi$.

As any numerical integration method delivers only an approximation to the integrals in Eq. $(A-2)$, we monitor the quality of the approximation by estimating the probabilistic error bound for the importance sampling estimator $\bar{\iota}_{n}$ ((Bauwens et al., 1999) chap. 3, Eq. 3.34). This error bound represents a $95 \%$ confidence interval for the percentage deviation of $\bar{\iota}_{n}$ from $\bar{\iota}$. It should not exceed $10 \%$.

Note that the normal approximation in Eq. $(A-6)$ selects $g(\psi \mid Y)$ in order to match the location and covariance structure of $p(\psi \mid y)$ as good as possible. One problem is that the normality assumption might imply that $\iota(\psi \mid Y)$ does not match the tail behavior of $p(\psi \mid Y)$. If $p(\psi \mid Y)$ has thicker tails than $\iota(\psi \mid Y)$, a draw $\psi^{(i)}$ from the tails of $\iota(\psi \mid Y)$ can imply an explosion of $z^{\iota}\left(\psi^{(i)}, Y\right)$. This is due to a very small value for $\iota(\psi \mid Y)$ being associated with a relatively large value for $p(\psi) p(Y \mid \psi)$, as the latter is proportional to $p(\psi \mid Y)$. Importance sampling is inaccurate in this case as this would lead to a weight $w_{i}$ close to one, i.e. $\bar{\iota}_{n}$ is determined by a single draw $\psi^{(i)}$. This is signalled by instability of the weights and a probabilistic error bound that does not decrease in $n$. In order to help prevent explosion of the weights, we change the construction of the importance density in two respects (Bauwens et al., 1999, chap. 3). First, we inflate the approximate covariance matrix $\widehat{\Omega}$ by multiplying it by a factor of 1.1. This reduces the probability that $p(\psi \mid Y)$ has thicker tails than $\iota(\psi \mid Y)$. Second, we use a sequential updating algorithm for the importance density. This algorithm starts from the importance density defined by $(A-6)$, with inflation of $\widehat{\Omega}$, estimates posterior moments for $p(\psi \mid Y)$ and then defines a new importance density from these estimated moments. This improves the estimates for $\widehat{\psi}$ and $\widehat{\Omega}$. We continue updating the importance density until the weights stabilize. The number of importance samples $n$ was chosen to make sure that the probabilistic error bound for the importance sampling estimator $\bar{\iota}_{n}$ does not exceed $10 \%$. 


\section{Posterior distribution of parameter and states}

An estimate $\widetilde{\psi}$ for the posterior mean $E[\psi \mid Y]$ of the parameter vector $\psi$ is obtained by setting $\iota\left(\psi^{(i)}\right)=\psi^{(i)}$ in Eq. $(A-4)$ and taking $\widetilde{\psi}=\bar{\iota}_{n}$. An estimate $\widetilde{\xi}_{t}$ for the posterior mean $E\left[\widehat{\xi}_{t} \mid Y\right]$ of the smoothed state vector $\widehat{\xi}_{t}$ is obtained by setting $\iota\left(\psi^{(i)}\right)=\widehat{\xi}_{t}^{(i)}$ in Eq. $(A-4)$ and taking $\widetilde{\xi}_{t}=\bar{\iota}_{n}$, where $\widehat{\xi}_{t}^{(i)}$ is the smoothed state vector obtained from the Kalman smoother using the parameter vector $\psi^{(i)}$. In order to calculate the 10th and 90th percentiles of the posterior densities of both the parameter vector $\psi$ and the smoothed state vector $\widehat{\xi}_{t}$, let $F\left(\psi_{j} \mid Y\right)=\operatorname{Pr}\left(\psi_{j}^{(i)} \leq \psi_{j}\right)$ with $\psi_{j}$ denoting the $j$-th element in $\psi$. An estimate $\widetilde{F}\left(\psi_{j} \mid Y\right)$ of $F\left(\psi_{j} \mid Y\right)$ is obtained by setting $\iota\left(\psi^{(i)}\right)=I_{j}\left(\psi_{j}^{(i)}\right)$ in Eq. $(A-4)$ and taking $\widetilde{F}\left(\psi_{j} \mid Y\right)=\bar{\iota}_{n}$, where $I_{j}\left(\psi_{j}^{(i)}\right)$ is an indicator function which equals one if $\psi_{j}^{(i)} \leq \psi_{j}$ and zero otherwise. An estimate $\widetilde{\psi}_{j}^{10 \%}$ of the 10 th percentile of the posterior density $p(\psi \mid Y)$ is chosen such that $\widetilde{F}\left(\psi_{j}^{10 \%} \mid Y\right)=0.10$. An estimate $\widetilde{\xi}_{j, t}^{10 \%}$ of the 10 th percentile of the $j$ th element of the posterior density $p\left(\widehat{\xi}_{t} \mid Y\right)$ is obtained by setting $\iota\left(\psi^{(i)}\right)=\widehat{\xi}_{j, t}^{(i)}-1.645 \sqrt{\widehat{P}_{j, t}^{(i)}}$ in Eq. $(A-4)$ and taking $\widetilde{\xi}_{j, t}^{5 \%}=\bar{\iota}_{n}$, where $\widehat{\xi}_{j, t}^{(i)}$ denotes the $j$-th element in $\widehat{\xi}_{t}^{(i)}$, and $\widehat{P}_{j, t}^{(i)}$ is the $(j, j)$ th element of the smoothed state variance matrix $\widehat{P}_{t}^{(i)}$ obtained using the parameter vector $\psi^{(i)}$. The 90th percentiles are constructed in a similar way. As such the posterior distribution of the smoothed state vector $\widehat{\xi}$ takes both parameter and filter uncertainty into account. 


\section{Tables and Figures}

Table 1: Test for structural breaks in inflation

\begin{tabular}{ccccccc}
\hline$W D_{\max }$ & $U D_{\max }$ & $\operatorname{SupF}_{T}(1 \mid 0)$ & $\operatorname{SupF}_{T}(2 \mid 1)$ & $\operatorname{SupF}_{T}(3 \mid 2)$ & $\operatorname{SupF}_{T}(4 \mid 3)$ & $\operatorname{SupF}_{T}(5 \mid 4)$ \\
\hline $76.31^{*}$ & $76.31^{*}$ & $66.36^{*}$ & $34.13^{*}$ & 5.71 & 2.34 & 1.72 \\
\hline
\end{tabular}

The maximum number of breaks is set to 5 . The $*$ denotes significance at the $5 \%$ level. The $5 \%$ critical values are $U D_{\max }=9.52, W D_{\max }=10.39, \operatorname{SupF}_{T}(1 \mid 0)=9.1, \operatorname{Sup}_{T}(2 \mid 1)=10.55, \operatorname{Sup} F_{T}(3 \mid 2)=11.36$, $\operatorname{SupF}_{T}(4 \mid 3)=12.35, \operatorname{SupF}_{T}(5 \mid 4)=12.97$.

Table 2: Prior and Posterior Parameter Distributions

\begin{tabular}{|c|c|c|c|c|c|}
\hline & \multirow[b]{2}{*}{ Parameter } & \multicolumn{2}{|c|}{ Prior Distribution } & \multicolumn{2}{|c|}{ Posterior Distribution } \\
\hline & & Mean & $90 \%$ Interval & Mean & $90 \%$ Interval \\
\hline \multirow[t]{8}{*}{ Output } & $a_{y_{0}}$ & 1.50 & {$[0.86,2.14]$} & 1.49 & {$[1.41,1.58]$} \\
\hline & $a_{y_{1}}$ & -0.70 & {$[-1.34,-0.06]$} & -0.58 & {$[-0.65,-0.50]$} \\
\hline & $a_{r_{0}}$ & -0.10 & {$[-0.51,0.31]$} & -0.03 & {$[-0.05,-0.01]$} \\
\hline & $a_{q_{0}}$ & 0.00 & {$[-0.50,0.50]$} & 0.04 & {$[0.02,0.07]$} \\
\hline & $a_{q_{1}}$ & 0.00 & {$[-0.50,0.50]$} & -0.05 & {$[-0.08,-0.03]$} \\
\hline & $\sigma_{y^{*}}^{2}$ & 0.25 & {$[0.08,0.47]$} & 0.10 & {$[0.06,0.14]$} \\
\hline & $\sigma_{g}^{2}$ & 0.25 & {$[0.08,0.47]$} & 0.01 & {$[0.01,0.02]$} \\
\hline & $\sigma_{\tilde{y}}^{2}$ & 0.50 & {$[0.16,0.92]$} & 0.22 & {$[0.17,0.28]$} \\
\hline \multirow[t]{7}{*}{ Inflation } & $\bar{\pi}_{1}$ & 6.00 & {$[1.94,10.05]$} & 6.81 & {$[6.19,7.42]$} \\
\hline & $\bar{\pi}_{2}$ & 3.00 & {$[3.13,8.87]$} & 3.58 & {$[3.19,3.98]$} \\
\hline & $\bar{\pi}_{3}$ & 1.00 & {$[-1.87,3.87]$} & 1.40 & {$[1.13,1.66]$} \\
\hline & $b_{y}$ & 0.50 & {$[0.21,0.79]$} & 0.22 & {$[0.13,0.30]$} \\
\hline & $b_{\pi}$ & 0.50 & {$[-0.14,1.14]$} & 0.20 & {$[0.14,0.26]$} \\
\hline & $b_{q}$ & -0.25 & {$[-0.38,-0.12]$} & -0.07 & {$[-0.11,-0.04]$} \\
\hline & $\sigma_{\pi}^{2}$ & 3.00 & {$[0.95,5.56]$} & 3.86 & {$[3.51,4.22]$} \\
\hline \multirow[t]{5}{*}{ Interest Rate } & $c$ & 4.00 & {$[3.09,4.91]$} & 3.74 & {$[3.21,4.28]$} \\
\hline & $\gamma$ & 0.00 & {$[-0.91,0.91]$} & 0.15 & {$[0.10,0.20]$} \\
\hline & $\rho$ & 0.50 & {$[-0.14,1.14]$} & 0.24 & {$[0.17,0.31]$} \\
\hline & $\sigma_{z}^{2}$ & 0.50 & {$[0.16,0.92]$} & 0.23 & {$[0.12,0.34]$} \\
\hline & $\sigma_{\kappa}^{2}$ & 0.50 & {$[0.16,0.94]$} & 3.34 & {$[3.04,3.65]$} \\
\hline \multirow[t]{4}{*}{ Exchange Rate } & $d_{q_{0}}$ & 1.50 & {$[0.86,2.14]$} & 1.30 & {$[1.20,1.41]$} \\
\hline & $d_{q_{1}}$ & -0.70 & {$[-1.34,-0.06]$} & -0.36 & {$[-0.46,-0.25]$} \\
\hline & $\sigma_{q^{*}}^{2}$ & 3.00 & {$[0.97,5.45]$} & 5.59 & {$[3.82,7.37]$} \\
\hline & $\sigma_{\tilde{q}}^{2}$ & 3.00 & {$[0.97,5.45]$} & 5.60 & {$[3.85,7.42]$} \\
\hline
\end{tabular}

The prior distribution is assumed to be Gaussian for all elements in $\psi$, except the variance parameters which are assumed to be gamma distributed. With $n=30,000$ for the initial importance function and all updates, the probabilistic error bound for the importance sampling estimator $\iota_{n}$ is well below $10 \%$ for all coefficients. 
Figure 1: Trend and cyclical components for output, the real interest rate and the real exchange rate
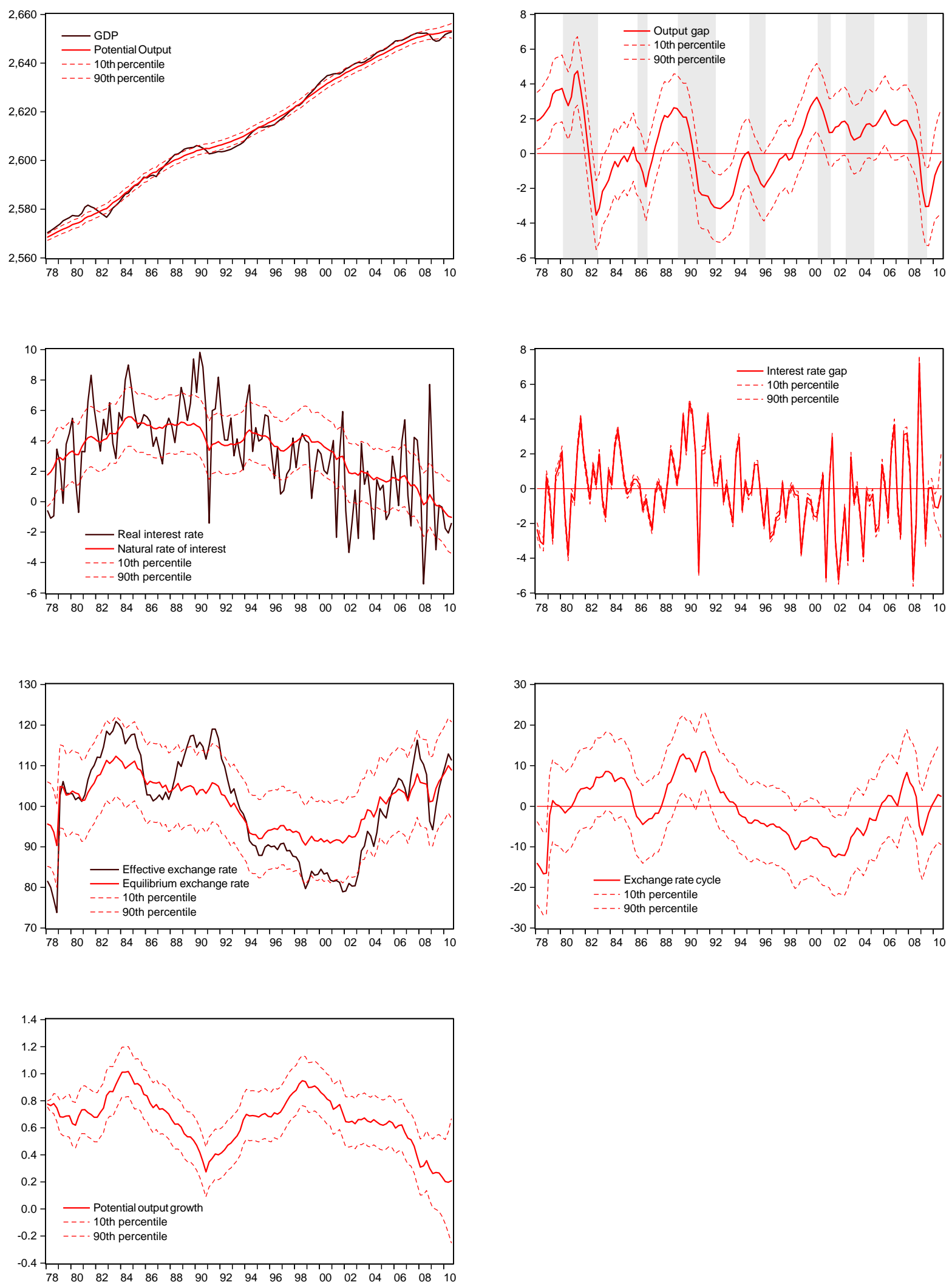


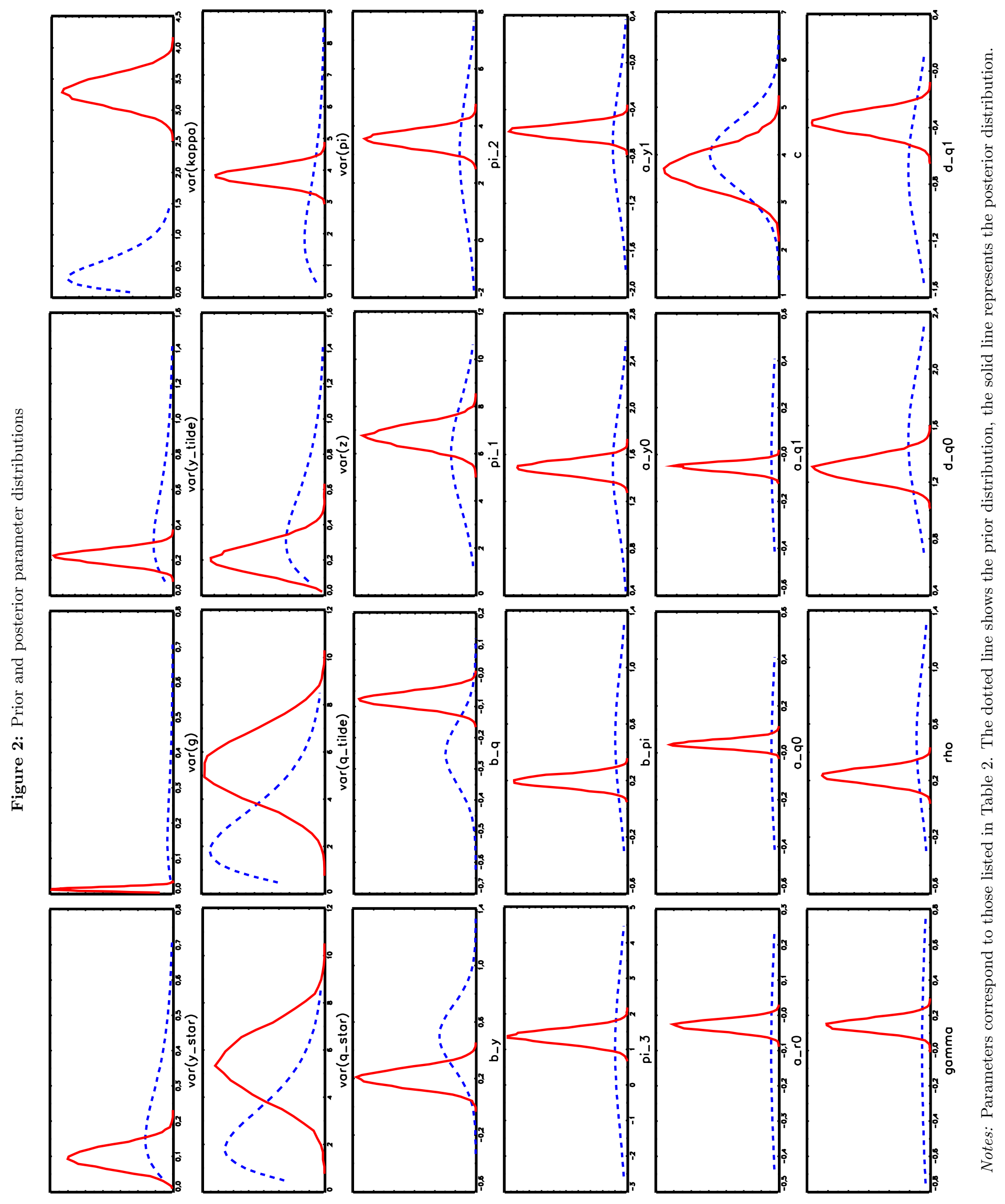


Figure 3: HP filtered trends and natural rates
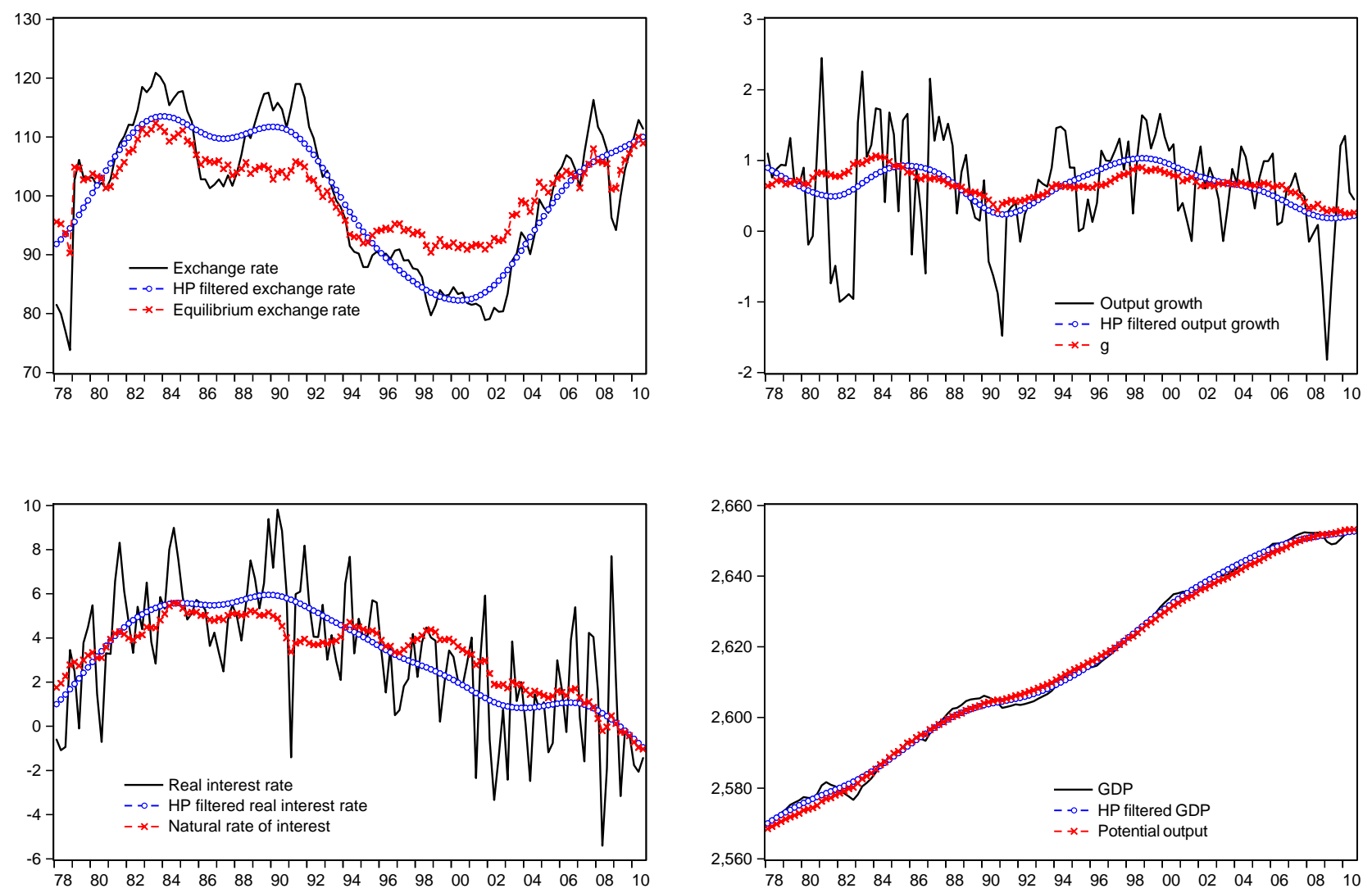
Figure 4: Natural rate of interest: baseline vs. constant growth model

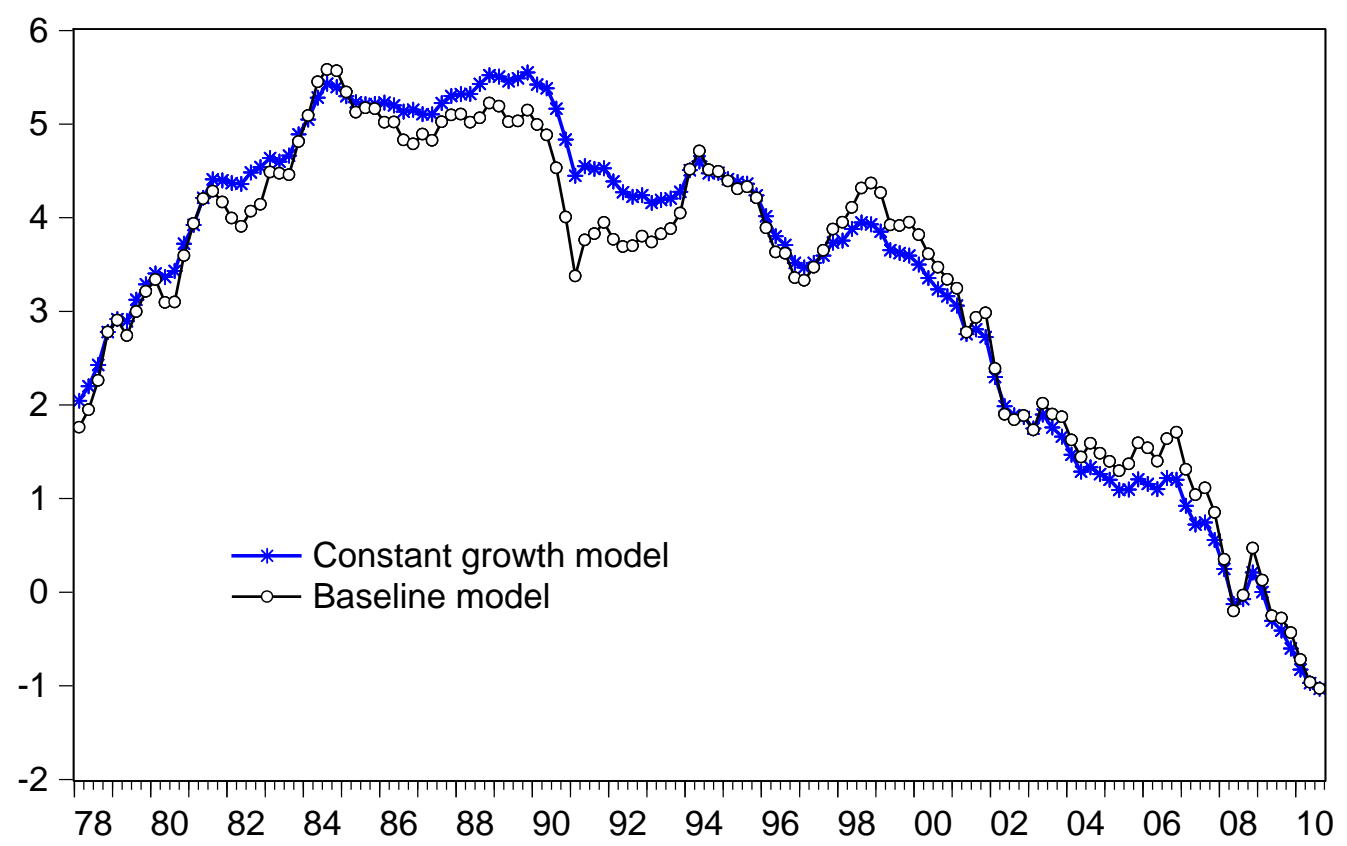

